\title{
Observation of hearing loss in patients with chronic suppurative otitis media tubotympanic type
}

Maharjan $\mathrm{M}^{1}$, Kafle $\mathrm{P}^{2}$, Bista $\mathrm{M}^{2}$, Shrestha $\mathrm{S}^{2}$, KC Toran ${ }^{3}$

${ }^{1}$ Lecturer, ${ }^{2}$ Assistant Professor, ${ }^{3}$ Associate Professor, Department of Ear Nose and Throat, Kathmandu Medical College

Teaching Hospital, Sinamangal, Nepal

\begin{abstract}
Background: It is acknowledged that size and site of tympanic membrane perforation is proportional to degree of hearing loss but there are many studies which suggests otherwise. Persistent ear discharge is also supposed to deteriorate hearing level with passage of time. This study is carried out to find out the relation between size and site of tympanic membrane perforation and duration of ear discharge on hearing loss.

Objectives: The objective of this study is to study the effect of size and site of tympanic membrane perforation and duration of ear discharge on hearing loss.

Materials and methods: This is a cross-sectional prospective study conducted at Kathmandu Medical College, department of ear nose and throat from January till July 2009. One hundred patients aged between 8 to 60 years with pars-tensa perforations were included in the study. Detail clinical examination and history was carried out followed by hearing evaluation by audiometry was done in all cases. All the data is collected, statistical analysis is done using SPSS program and documented for study.

Results: One hundred patients with 119 perforated tympanic membrane, age ranged between 8 to 60 years, 44 males and 56 females were studied. Bilateral tympanic membrane perforation were seen in 19 patients, right sided perforation in 39 and left sided in 42 patients respectively. Large central perforation involving all four quadrants was the most common otologic findings seen in 72 ears $(60.50 \%)$ whereas perforation in posterosuperior quadrant was the least common finding seen in 3 patients $(2.52 \%)$. Significant relation is observed between site of perforation and degree of hearing loss; posterior placed perforations seem to have larger hearing loss. Ninety-five perforations (79.83\%) showed more loss in low frequencies with larger air bone gap at low frequencies. The longer the duration of ear discharge, the more the hearing loss.
\end{abstract}

Conclusion: The larger the perforation, the greater the decibel loss in sound perception. The location of perforation on the tympanic membrane and the duration of ear discharge have significant effect on the magnitude of hearing loss.

Key words: chronic suppurative otitis media, tympanic membrane perforation, hearing loss

$\mathrm{C}$ hronic suppurative otitis media has been an important cause of middle ear disease since prehistoric period 1 and it is the most important cause of hearing loss in developing countries like Nepal2. Poor and overcrowded living conditions, poor hygiene and nutrition have been suggested as a basis for the widespread prevalence of chronic suppurative otitis media in developing countries 1 .

Tubotympanic type of chronic suppurative otitis media is characterized by a perforation of pars tensa; perforations vary in size and site. Tympanic membrane not only performs the conduction of sound waves across the middle ear but also serves a protection function to the middle ear cleft and shields the round window from direct sound waves which is referred to as "round window baffle" 3 . This shield is necessary to create a phase differential so that the sound wave doesn't impact on the oval and round window simultaneously. This would dampen the flow of sound energy being transmitted in a unilateral direction from the oval window through the perilymph. It has been found that the effect of the enhanced ration of the surface area of the tympanic membrane to that of the oval window increase the sound pressure by about 27 decibel where as the lever action of ossicles contributes only about 3 decibel4,5. A perforation on the tympanic membrane reduces the surface area of the membrane available for sound pressure transmission and allows sound to pass directly into middle ear.

\section{Correspondence}

Dr. Milan Maharjan

Lecturer, Department of Ear Nose and Throat

Kathmandu Medical College Teaching Hospital

E-mail: puntoo@hotmail.com 
Perforations of the tympanic membrane cause a conductive loss that can range from negligible to $50 \mathrm{~dB}$. It has been established that the larger the perforation, the greater the decibel loss in sound perception. A total absence of the tympanic membrane would lead to a loss in the transformer action of the middle ear6.

Similarly the location of the perforations also have significant impact on the magnitude of hearing loss7, posterior quadrant perforations are believed to be worse than the anterior ones because of the direct exposure of the round window to sound waves. Perforations at or near the site of tympanic membrane attachment to manubrium have more severe effects than those of comparable size at different sites. This study is carried out to find out the effect of site and size of tympanic membrane perforation and duration of ear discharge on hearing loss in Tubotympanic type of chronic suppurative otitis media.

\section{Materials and methods}

This is a cross-sectional prospective study conducted at out patient's division at the Ear Nose and Throat department of Kathmandu Medical College, Kathmandu from January till July 2009. One hundred patients aged between 8 to 60 years with pars-tensa perforations were included in this study.

The patient's age at presentation, sex, duration of ear discharge and previous history of ear disease were documented. Clinical examination is carried out by single consultant to avoid variations using WelchAllyn otoscope. For the purpose of the study tympanic membrane is divided into four quadrants; anterosuperior (AS), posterosuperior (PS), anteroinferior (AI) and posteroinferior (PI) respectively. Size of tympanic membrane perforation is classified as small (perforation involving single quadrant), medium (perforation involving two quadrants) and large (perforation involving more than three quadrants).

The patient's hearing levels in decibel were assessed with calibrated audiometer ( Intra-acoustic, Denmark, AD229E, AC:ISO 389-1 (TDH39 ), ISO 389-2 (EARTone 3A), BC: ISO 389-3) at frequencies $250 \mathrm{KH}$, $500 \mathrm{KH}, 1000 \mathrm{KH}, 2000 \mathrm{KH}, 4000 \mathrm{KH}$ and $8000 \mathrm{KH}$ respectively in acoustically treated sound proof room by a experienced audiologist. Air and bone conduction thresholds were determined and documented. The mean hearing loss was calculated through the pure tone average taken at $500 \mathrm{~Hz}, 1000 \mathrm{~Hz}, 2000 \mathrm{~Hz}$ and 4000 Hz. Hearing loss was classified according to WHO classification8. Data were analysed using SPSS program for statistical evaluation. Cases with active discharge, traumatic perforation, post-ventilation tube insertion perforation, and otitis media with cholesteatoma and with mixed hearing loss were excluded from the study.

\section{Results}

A total of 119 ears in 100 patients, age ranged between 8 to 60 years (mean 34 years) were studied. There were 44 males and 56 females. Bilateral tympanic membrane perforation was seen in 19 patients, right sided perforation in 39 patients and left sided in 42 patients respectively.

Large central perforation involving all the four quadrants was by far the most commonly affected, being involved in 72 cases $(60.50 \%)$ Perforation involving posterosuperior and posteroinferior quadrants was seen in 6 cases $(5 \%)$, anterosuperior and anteroinferior quadrants in 15 cases $(12.60 \%)$, posteroinferior and anteroinferior quadrant in 12 cases $(10.08 \%)$, posteroinferior quadrant in 7 cases $(5.82 \%)$, anteroinferior quadrant in 4 cases $(3.36 \%)$ and perforation in posterosuperior quadrant was the least common finding seen in 3 cases $(2.52 \%)$. Perforation involving anterosuperior quadrant was not recorded in any of the cases.

Hearing status of all 119 perforated tympanic membrane is mild loss 29 (24.37\%), moderate loss 63 (52.94\%), moderate severe loss $24(20.17 \%)$ and severe loss 3 $(2.52 \%)$.

Analysis of the pure tone audiogram of 96 patients $(80.67 \%)$ showed more loss in low frequencies with larger air bone gap at low frequencies. Remaining 23 patients $(19.32 \%)$ showed loss involving all the frequencies.

Patients with larger perforation involving four quadrants showed greater hearing loss with large air bone gap. Out of 72 cases with large perforations involving four quadrants 45 perforations have moderate conductive hearing loss, 22 cases have moderately severe loss, 3 have severe loss and only 2 cases have mild conductive loss. Where as patients with smaller perforation involving single quadrant showed lesser loss. We found a significant relationship between hearing loss and size of perforation ( $\mathrm{p}$-value $<0.05$ ), with a strong trend for hearing loss to increase as the perforation size increases.

Statistically significant relation is observed between site of perforation and degree of hearing loss; posterior placed perforations seem to have larger hearing loss. Three cases with posterosuperior quadrant perforation, all three patients have moderate degree hearing loss. Relation between anterior based perforation with degree of hearing loss was not significant, p-Value: 0.422 . Whereas there is significant correlation between posterior based perforation and hearing loss, p-Value: 0.000 
We found strong relation between duration of ear discharge and degree of hearing loss. The relation between duration of ear discharge and degree of hearing loss was statistically significant with P-Value 0.023 . The longer the duration of hearing loss the larger the perforation and the more the hearing loss. Sixty two patients $(62 \%)$ have a history of ear discharge for more than 10 years, $38(38 \%)$ with a history of ear discharge for less than 10 years. Out of 62 patients 50 (80.64\%) of them have large central perforation involving all four quadrants. Thirty $(60 \%)$ out of 50 patients with large central perforation have moderate conductive hearing loss, $16(32 \%)$ have moderate severe hearing loss where as only $4(8 \%)$ of the patients have mild hearing loss.

Table 1: Posterior versus anterior quadrant perforation and it's relation with degree of hearing loss

\begin{tabular}{|l|c|c|c|c|c|c|c|}
\hline & \multicolumn{7}{|c|}{ Hearing loss } \\
\hline Site of perforation & Mild & Moderate & Moderately severe & Severe & Normal & Total & P-Value \\
\hline Anterior & $21 \%$ & $42 \%$ & $18 \%$ & $3 \%$ & $16 \%$ & $100 \%$ & 0.422 \\
\hline Posterior & $9 \%$ & $51 \%$ & $19 \%$ & $3 \%$ & $18 \%$ & $100 \%$ & 0.000 \\
\hline
\end{tabular}

*Chi- square test applied (pooling technique applied)

Table 2: Duration of ear discharge and it's relation with degree of hearing loss

\begin{tabular}{|l|c|c|c|c|c|c|}
\hline & \multicolumn{5}{|c|}{ Hearing loss } \\
\hline Duration of ear discharge & Mild & Moderate & Moderately severe & Severe & Total & P-Value \\
\hline$<10$ years & $15 \%$ & $18 \%$ & $3 \%$ & $2 \%$ & $38 \%$ & 0.023 \\
\hline$>10$ years & $11 \%$ & $34 \%$ & $16 \%$ & $1 \%$ & $62 \%$ & \\
\hline Total & $26 \%$ & $52 \%$ & $19 \%$ & $3 \%$ & $100 \%$ & \\
\hline
\end{tabular}

*Chi-Square test applied

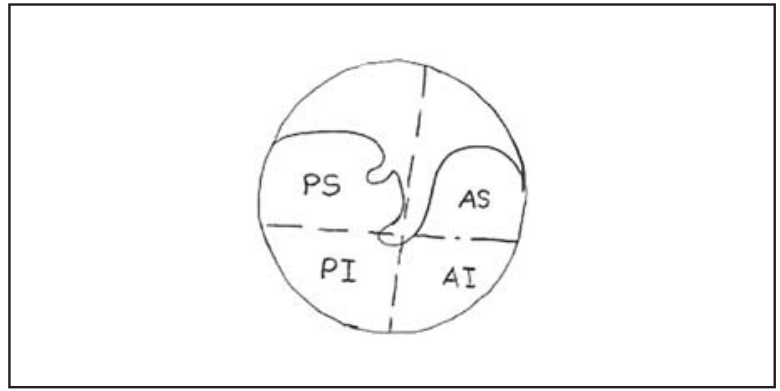

Fig 1: Division of tympanic membrane

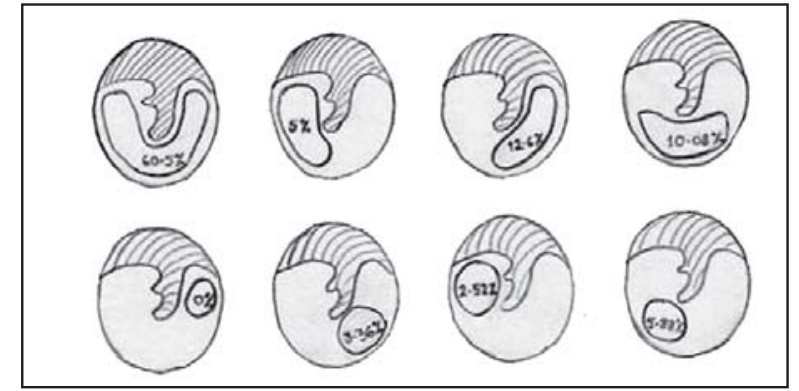

Fig 2: Site of perforations

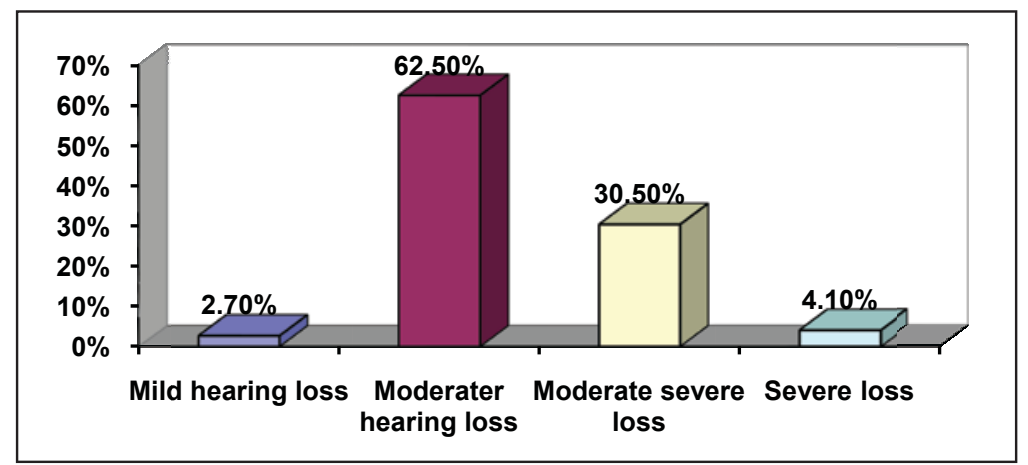

Fig 3: Large central perforation and it's relation to degree of hearing loss 


\section{Discussion}

Chronic suppurative otitis media with perforation of pars tensa is one of the main causes of conductive hearing loss in developing countries like ours. Sakagami $\mathrm{M}$ et al9 observed that chronic suppurative otitis media as main cause of hearing loss, in which 82 out of 91 cases with chronic suppurative otitis media had an tympanic membrane perforation with intact ossicular chain. Therefore the main cause of conductive hearing loss was tympanic membrane perforation and not any other middle ear pathology. In order to provide better hearing and to protect middle ear cleft from further complications myringoplasty should be considered in all cases.

In our study like in other studies; Walter P et al10, Voss SE et al11, Ahmed SW et al7, Nepal A et al12, Ibekwe TS et al13, Oluwole M et al14 and Mehta RP et al15, we found that the larger the perforation on the tympanic membrane the greater the decibel loss in sound perception.

The potential effect of loss of the "round window baffle" on hearing threshold demonstrated in our study. Perforationinvolvingposterosuperiorandposteroinferior quadrant were found to have maximum hearing loss as compared to perforation involving anteroinferior or anterosuperior quadrant, which was also found in other studies carried out by Ahmed SW et al7. Although no statistical significant relation was observed between site of perforation and degree of loss, posterior placed perforations seem to have relatively larger hearing loss. Such observation was made by Voss SE et al11, Nepal A et al12, Bhusal CL et al16 and Ibekwe TS et al13. Unlike this Mehta RP et al15 and Oluwole M et al14 did not observe significant differences in the hearing loss in anterior versus posterior quadrant perforations.

The conductive hearing loss resulting from tympanic membrane perforation is frequency dependent, with the largest losses occurring at lower frequencies. Similar findings was also observed in our study as well in studies carried out by Mehta RP et al15, Voss SE et al11, Ahmed SW et al7 and Bhusal CL et al16.

Majority of patients with larger air bone gap were found to have discharging ear for longer duration as compare to those with lesser degree of hearing loss. Air conduction hearing levels deteriorates with the passage of time; similar observation was made in our study and also by Sakagami M et al9.

\section{Conclusion}

The larger the perforation, the greater the decibel loss in sound perception. Large central perforations involving all four quadrants results in more degree of hearing loss.
The location of perforation on the tympanic membrane has significant effect on hearing loss. Posterior placed perforations have greater degree of loss. The conductive hearing loss resulting from tympanic membrane perforation is frequency dependent, with the largest losses occurring at lower frequencies. Duration of ear discharge also have significant effect on the magnitude of hearing loss, the longer the duration of ear discharge the greater the hearing loss.

\section{References}

1. Booth JB. Management of chronic suppurative otitis media. Scott-Brown's Otology. 1997; $3: 10-1$

2. Shrestha R, Baral K, Neil W. Community ear care delivery by community ear assistants and volunteers: a pilot study. J. Laryngol Otol. 2001; 115:869-73.

3. Ogisi FO, Adobamen P. Type I Tympanoplasty in Benin: A 10 year review. The Nigerian Postgraduate Medical journal. 2004; 11:84-7.

4. Voss SE, Rosowski JJ, Merchant SN, Peake WT. Non-ossicular signal transmission in human middle ears: Experimental assessment of the "acoustic route" with perforated tympanic membranes. J Acoust Soc Am. 2007; 122:213553.

5. Shamb Baugh GE. Surgery of the ear. Philadelphia WB Saunder. 1959; 336-7.

6. American Academy of Otolaryngology-Head and neck. Perforated Ear Drum. US: American Academy of Otolaryngology-Head and neck; 2005.

7. Ahmad SW, Ramani GV. Hearing loss in tympanic membrane perforations. JLO. 1979; 93:1091-8

8. Biswas A. Pure tone audiometry: Clinical audiovestibulometry. 2002; 1-23.

9. Sakagami M, Maeda A, Node M, Sone M, Mishiro Y. Long-term observation on hearing change in patients with chronic Otitis media. Auris Nasus Larynx. 2000;27(2):117-20.

10. Walter PA, Clell WH. Tympanic membrane perforation. Effect on Audiogram. Arch Otolaryngol. 1972; 95(6):506-10.

11. Voss SE, Rosowski JJ, Merchant SN, Peake WT. How do tympanic membrane perforations cause conductive hearing loss. Session J, Podium. 1998; 263 .

12. Nepal A, Bhandary S, Mishra SC, Singh I, Kumar P. The morphology of central tympanic membrane perforations. Nepal Medical College Journal. 2008;9(4);239-44. 
13. Ibekwe IS, Nwaorgu OG, Ijaduola TG. Correlationg the site of tympanic membrane perforation with Hearing loss. MBC Ear, Nose and Throat Disorders. 2009,9:1.

14. Oluwole M, Mills RP. Tympanic membrane perforations in children. International Journal of Pediatric Otorhinolaryngology. 1996;36:11723.
15. Mehta RP, Rosowske JJ, Voss SE, O’Neil E, Merchant SN. Determinants of hearing loss in perforations of the tympanic membrane. Otol Neurotol. 2006;27(2):136-43.

16. Bhusal CL, Guragain RP, Shrivastav RP. Frequency dependence of hearing loss with perforations. JNMA J Nepal Med Assoc. 2007;46(168):180-4. 